\title{
Contractile properties of lower leg muscles are normal in Parkinson's disease
}

\author{
A Hufschmidt, K Stark, C H Lücking
}

\begin{abstract}
Contraction parameters (time-to-peak and half relaxation time), responses to short tetani and resistance to stretch were studied in the lower leg muscles of Parkinsonian patients and in agematched controls. It was possible to distinguish between muscle groups of different fibre type composition in normal subjects on the basis of their contraction and relaxation velocities. These parameters, however, failed to show any abnormalities in the patient group. The only abnormal finding in Parkinsonian subjects was an increased resistance to passive stretch under static conditions, presumably elastic in origin. The results are evidence against a contribution of altered contractile properties to muscular rigidity in Parkinsonism.
\end{abstract}

The pathophysiology of rigidity is still controversial. Among the mechanisms thought to contribute to the tone increase in Parkinson's disease (PD) are: enhanced flexor reflexes with responses appearing also in antagonist muscles, ${ }^{12}$ disinhibited tonic stretch reflexes ${ }^{3}$ as well as abnormal long-loop reflexes. ${ }^{4-6}$ Current theory agrees that the lower motor neuron is the final common pathway over which rigidity is expressed. Electromyographic recordings of lower leg muscles in Parkinsonian and spastic patients during walking have, however, failed to show an increase in activity in the gastrocnemius muscle while it was stretched during the swing phase. ${ }^{7}$ In the upper extremity of Parkinsonian subjects, the neutral angle of the elbow joint has been shown to be smaller than in normal controls, and stiffness is enhanced in the absence of EMG activity. ${ }^{8}$ As a result, it has been suggested that both rigidity and spasticity arise partly from altered mechanical properties of the muscles. Lower leg muscles of patients with long-standing spasticity have indeed been shown to have some increase in plastic stiffness. ${ }^{9}$ The actual contribution, however, of this change to the overall increase in tone, as well as to the disability experienced by the patient, remains open.

The influence of neuronal discharge patterns on the differentiation of skeletal muscle is well established and has been demonstrated after spinal transsections, ${ }^{10}$ cross-reinnervation of fast and slow units ${ }^{11-14}$ and long-term stimulation. ${ }^{15-17}$ Thus a relationship between altered central innervation patterns and changes in muscular properties is conceivable.
Muscles of spastic patients have delayed contraction times. ${ }^{18-20}$ As yet, there are no comparable data for PD. Morphological and histochemical studies of this condition have revealed an atrophy of fast (Type II) and hypertrophy of slow (Type I) fibres. ${ }^{21}$ In addition, ultrastructural abnormalities have been shown, in particular, defects of the outer mitochondrial membrane and disarrangement of the contractile filaments. ${ }^{22}$ It is not, however, known whether these changes affect muscle tone.

Direct measurements of muscle stiffness using imposed movements are difficult in Parkinsonism, due to shortening reactions, which are more frequent in extrapyramidal disorders, ${ }^{23}$ and which may lead to gross under-estimation of the passive resistance to stretch. In this study, responses to single twitches and to brief tetanic trains were recorded under resting conditions and during passive movements of the ankle. We have failed to demonstrate any abnormality in the contractile properties of lower leg muscles in Parkinsonian patients.

\section{Methods \\ Subjects}

The experiments were performed on 16 Parkinsonian patients (mean age 67.8 years, male $/$ female $=11 / 5$ ) and 18 controls (mean age 63.7 years, $m / f=9 / 9$ ), who had no history or clinical signs of motor abnormalities. For statistical comparison of the two groups, the two youngest normal subjects were eliminated from the control group (thus $\mathrm{n}=16$, mean age 65.4 years, $\mathrm{m} / \mathrm{f}=9 / 7$ ). The subjects gave their informed consent to the procedures involved in the study. The patients were Grade 3 and 4 according to the Hoehn and Yahr scale. All were receiving anti-Parkinsonian treatment, including levodopa.

\section{Experimental procedure}

The subjects were seated comfortably in a chair and were instructed to relax their legs as completely as possible. One foot was strapped to a pedal which could either be locked into place or moved by a torque motor. The axis of the pedal was aligned approximately with the subject's ankle. The twitch force (later converted to ankle torque) and the resisting torque during passive movement were measured by strain-gauges registering a minimal deformation of the pedal along a breaking-line. Tension will therefore be given 
as ankle torque in this paper. Assuming a relationship between force output and crosssectional area, all tension values were normalised to a standard calf with a cross-sectional area corresponding to a maximum circumference of $35 \mathrm{~cm}$. The torque and position signals were digitised and stored by a Nicolet 1070 averager and then passed on to an Apple $\mathrm{II}+$ computer for further evaluation. The subject's lower leg was positioned so that the tibial edge was perpendicular and at a right angle to the sole of the foot. Muscles were stimulated with brief $(0 \cdot 1-1 \mathrm{~ms})$, currentstabilised square-wave pulses of up to $25 \mathrm{~mA}$ at the motor point, with the second electrode positioned over the distal tendon. For the triceps surae muscle, stimuli were applied to one head of the gastrocneumius muscle. There was often also a twitch of the soleus muscle elicited by the indifferent electrode.

Experiments 1 and 2, involving isometric twitches and tetani, were performed on the tibalis anterior and the triceps surae muscle:

1 Isometric twitches at near-threshold intensity ("weak twitch"), near the tolerance threshold intensity ("strong twitch"), and at an intermediate intensity ("intermediate twitch"; stimulating current mid-way between the previous two). The tolerance threshold, as a rule, was reached at two to three times motor threshold intensity. The intermediate stimulus intensity was maintained for the subsequent tetanic stimulation experiments. Recorded parameters were: peak tension (PT), time-to-peak (TTP), and halfrelaxation time (HRT).

2 Isometric tetani were applied as brief trains (5 pulses) at 10, 20, 40,60 and $100 \mathrm{~Hz}$. Peak tension (PT) was recorded. The twitch/ tetanus ratio was computed as the quotient between peak tensions for the "intermediate" twitch and the $100 \mathrm{~Hz}$ tetanus, the stimulus intensity being identical in the two conditions.

Experiments 3 and 4 involved controlled stretches:

3 Elastic stiffness. The foot was slowly (6.6 $\mathrm{deg} / \mathrm{s}$ ) dorsiflexed by the pedal and then maintained in a 10 degree dorsiflexed position for $4.7 \mathrm{~s}$. Elastic stiffness was calculated from the difference in ankle torque at the starting position and at the dorsiflexed position immediately before the return of the pedal, that is, after termination of phasic stretch responses.

4 Stiffness of stimulated muscle. The influence of low-level activation on the resistance to stretch was imitated by $10 \mathrm{~Hz}$ tetanic stimulation ( 5 pulses) of the triceps surae muscle while it was being slowly stretched at a rate of $16 \mathrm{deg} / \mathrm{s}$ of ankle dorsiflexion. The first impulse of the train was delivered $100 \mathrm{~ms}$ after onset of the passive movement. As a control condition, the same stretch was imposed without stimulation. Tension increase was measured as the difference between the peak tension during stretch under tetanic stimulation and (in the control runs without stimulation) the resting tension at the point where peak tension had occurred in the previous condition. In the tetanically stimulated muscle, the resistance to stretch (stiffness) was compared with the active tension by the stiffness ratio

$$
\mathbf{R}_{\text {stiff }}=\frac{\text { tetanic tension of stretched muscle }}{\text { tetanic tension of resting muscle }}
$$

which is invariably $>1$, reflecting the fact that the tetanically stimulated muscle resists stretch with a force far greater than its contractile force.

Trials with superimposed shortening reactions could be identified by irregular deformations of the length-tension curve and were discarded.

\section{Results}

Normal subjects

The absolute twitch force, in our experiments, was a poorly controlled parameter and varied considerably between subjects. We must begin therefore by showing that the kinetic parameters are not dependant on twitch amplitude. This has been done by comparing TTP and HRT at the three different levels of stimulus intensity. Table 1 shows that there are no systematic changes of contraction or relaxation velocity with changes in stimulation intensity.

Both parameters of twitch duration (TTP and HRT) were significantly shorter in the tibialis anterior compared with the triceps surae (table 1). This reflects the difference in fibre type composition: the ratio of Type I: Type II fibres is $46: 54$ for tibialis anterior, but between 82:18 (gastrocnemius, lateral head) and 89:11 (soleus) for the triceps surae. ${ }^{24}$ The difference was not, however, reflected in the tetanic PT at increasing frequencies.

There was a significant co-variation $(r=$ $0.75 ; p<0.001)$ of TTP and HRT for strong twitches in the tibialis anterior, suggesting that contraction velocities are scattered over a certain range within the control group. Correlations for weak and intermediate twitches as well as for the triceps surae (all twitches) were non-significant.

Table 1 Contraction parameters of lower leg muscles in elderly normal subjects $(n=18)$. PT: peak tension, TTP: time-to-peak, HRT: half-relaxation time.

\begin{tabular}{|c|c|c|}
\hline & $\begin{array}{l}M \text { tibialis ant. } \\
\text { mean (SD) }\end{array}$ & $\begin{array}{l}M \text { triceps surae } \\
\text { mean }(S D)\end{array}$ \\
\hline $\begin{array}{l}\text { Weak twitch } \\
\text { PT (Nm) } \\
\text { TTP (ms) } \\
\text { HRT (ms) }\end{array}$ & $\begin{array}{c}0.169(0 \cdot 115) \\
98 \cdot 7(12 \cdot 6) \\
103.2(25 \cdot 2)\end{array}$ & $\begin{array}{l}0.159(0.134) \\
113.7(26.5) \\
135.0(54 \cdot 1)\end{array}$ \\
\hline $\begin{array}{l}\text { Intermediate twitch } \\
\text { PT (Nm) } \\
\text { TTP (ms) } \\
\text { HRT (ms) }\end{array}$ & $\begin{array}{l}0.335(0 \cdot 163) \\
90 \cdot 2(10 \cdot 7) \\
98 \cdot 1(23.0)\end{array}$ & $\begin{array}{l}0.378(0.266) \\
118.3(21 \cdot 4) \\
146.6(32.6)\end{array}$ \\
\hline $\begin{array}{l}\text { Strong twitch } \\
\text { PT (Nm) } \\
\text { TTP (ms) } \\
\text { HRT (ms) }\end{array}$ & $\begin{array}{l}0.504(0.280) \\
90.0(12.5) \\
92.7(25.3)\end{array}$ & $\begin{array}{l}0.595(0.476) \\
114.7(20 \cdot 1) \\
139.1(31.7)\end{array}$ \\
\hline $\begin{array}{c}\text { Peak tetanic tension } \\
100 \mathrm{~Hz}(\%) \\
60 \mathrm{~Hz}(\%) \\
40 \mathrm{~Hz}(\%) \\
20 \mathrm{~Hz}(\%) \\
10 \mathrm{~Hz}(\%) \\
\text { Twitch/tetanus }\end{array}$ & $\begin{array}{l}100 \\
100 \cdot 7(26 \cdot 1) \\
93 \cdot 4(18 \cdot 3) \\
93 \cdot 0(15 \cdot 1) \\
70 \cdot 3(21 \cdot 2) \\
0 \cdot 22(0 \cdot 10)\end{array}$ & $\begin{array}{l}100 \\
96 \cdot 2(14 \cdot 8) \\
92 \cdot 9(20 \cdot 3) \\
98 \cdot 1(20 \cdot 2) \\
82 \cdot 2(18 \cdot 3) \\
0.24(0 \cdot 13)\end{array}$ \\
\hline
\end{tabular}

${ }^{\star} \mathrm{p}<0.01$ (Wilcoxon test for paired samples)

ns, not significant. 
Table 2 Contraction parameters of lower leg muscles in Parkionian patients $(\boldsymbol{n}=16)$ and age-match normal controls $(n=16)$; mean (SD). PT: peak tension, TTP: timeto-peak, HRT: half-relaxation time. There are no significant differences between the groups (Wilcoxon test for independent samples).

\begin{tabular}{|c|c|c|c|c|}
\hline & \multicolumn{2}{|c|}{$M$ tibialis ant. mean (SD) } & \multicolumn{2}{|c|}{$M$ triceps surae mean (SD) } \\
\hline & $P D$ & Controls & $P D$ & Controls \\
\hline $\begin{array}{l}\text { Weak twitch } \\
\text { PT (Nm) } \\
\text { TTP (ms) } \\
\text { HRT (ms) }\end{array}$ & $\begin{array}{l}0.191(0.135) \\
95.9(22 \cdot 2) \\
95.3(18 \cdot 5)\end{array}$ & $\begin{array}{c}0 \cdot 166(0 \cdot 116) \\
99 \cdot 8(12 \cdot 6) \\
105 \cdot 4(25 \cdot 8)\end{array}$ & $\begin{array}{l}0.177(0.189) \\
110.5(24 \cdot 7) \\
120 \cdot 2(37.8)\end{array}$ & $\begin{array}{l}0.154(0.142) \\
112.0(27 \cdot 6) \\
129 \cdot 7(55 \cdot 2)\end{array}$ \\
\hline $\begin{array}{l}\text { Intermediate twitch } \\
\text { PT (Nm) } \\
\text { TTP (ms) } \\
\text { HRT (ms) }\end{array}$ & $\begin{array}{c}0.276(0 \cdot 161) \\
87 \cdot 3(22 \cdot 5) \\
89 \cdot 9(24 \cdot 1)\end{array}$ & $\begin{array}{c}0.335(0.157) \\
91 \cdot 9(9 \cdot 7) \\
100 \cdot 6(23 \cdot 1)\end{array}$ & $\begin{array}{c}0.390(0.497) \\
120 \cdot 7(29 \cdot 5) \\
144 \cdot 7(58.6)\end{array}$ & $\begin{array}{l}0.339(0.255) \\
117.3(22.6) \\
144.7(33.8)\end{array}$ \\
\hline $\begin{array}{l}\text { Strong twitch } \\
\text { PT (Nm) } \\
\text { TTP (ms) } \\
\text { HRT (ms) } \\
\text { Twitch/tetanus }\end{array}$ & $\begin{array}{l}0.409(0 \cdot 186) \\
84.5(18 \cdot 6) \\
93 \cdot 3(22 \cdot 7) \\
0 \cdot 28(0 \cdot 14)\end{array}$ & $\begin{array}{c}0.527(0.275) \\
92.5(9 \cdot 1) \\
97.8(21 \cdot 7) \\
0.22(0.10)\end{array}$ & $\begin{array}{c}0.659(0.626) \\
115 \cdot 1(27 \cdot 4) \\
132 \cdot 0(30 \cdot 9) \\
0.27(0 \cdot 11)\end{array}$ & $\begin{array}{c}0.490(0.389) \\
112.4(19 \cdot 8) \\
140.1(33 \cdot 6) \\
0.25(0.13)\end{array}$ \\
\hline
\end{tabular}

Patients with Parkinson's disease

The patient group did not show any slowing of TTP or HRT compared with the control group (table 2). The curves relating the frequency of tetanic stimulation to tetanic PT lay as close together as in normal subjects and did not saturate earlier, as might have been expected in slower muscles. The only abnormality found in the patient group was a twofold increase in the passive resistance to stretch under static conditions (table 3).

\section{Discussion}

Two mechanisms are conceivable by which altered muscle properties may contribute to rigidity. Firstly, the elastic stiffness of muscle and joint capsule may be enhanced by fibrosis. Secondly, a transformation of the contractile apparatus may result in a disproportional increase in stiffness at low rates of stimulation. It would be expected that the latter abnormality would be seen to some degree when the fibre type composition of a muscle is shifted towards slow (Type I) fibres, with a lower tetanic fusion frequency. This should manifest itself as a slowing of contraction and relaxation of the whole muscle and as a large increase in stiffness when the muscle is stretched during low rate tetanic stimulation.

This study failed to produce any evidence for a slowing of intrinsic muscular contraction in the lower leg muscles of Parkinsonian patients. It is unlikely that this failure is attributable to a lack of sensitivity of our recording equipment, as the method was able to show differences in contraction kinetics between the tibialis anterior and triceps surae muscles in normal subjects. Furthermore, we found an interindividual co-variation between TTP and

Table 3 Passive elastic and tetanic stiffness of $M$ triceps surae in Parkinsonian patients and normal controls, mean (SD).

\begin{tabular}{lll}
\hline & $\begin{array}{l}\text { Parkinson's } \\
\text { disease }\end{array}$ & Controls \\
\hline Elastic stiffness $(\mathrm{Nm} / \mathrm{deg})$ & $\begin{array}{l}117 \cdot 0(135 \cdot 7) \\
(\mathrm{n}=15)\end{array}$ & $\begin{array}{l}60 \cdot 3(27 \cdot 9) \\
(\mathrm{n}=13)\end{array}$ \\
$\begin{array}{l}\text { Stiffness ratio } \\
\text { (tetanic tension with/ } \\
\text { without stretch) }\end{array}$ & $\begin{array}{l}19 \cdot 4(9 \cdot 4) \\
(\mathrm{n}=13)\end{array}$ & $\begin{array}{l}20 \cdot 1(8 \cdot 3) \quad \mathrm{ns} \\
(\mathrm{n}=9)\end{array}$ \\
\hline
\end{tabular}

${ }^{\star} p<0.025$ (Wilcoxon test for independent samples). ns, not significant.
HRT for the tibialis anterior which obviously reflects individual differences in contraction velocity within the control group. If the method is sensitive enough to detect these differences, it should also be able to record changes related to rigidity. The quantification of peak tension during short tetani was found to be of little use in this context and did not even reveal noticeable differences between muscle groups of different fibre type composition in normal subjects. To spare our subjects from extremely painful sustained tetanic stimulation, we confined ourselves to very brief trains of five stimuli. This is probably insufficient to reach a steady state of tetanic tension, and therefore inadequate as a means of detecting differences in tetanic fusion frequency.

Our only abnormal finding in Parkinsonian patients was an increase in the resistance to passive dorsiflexion. A similar finding has been made in the upper extremities of Parkinsonian subjects, who exhibited a shift of the resting position of the elbow towards flexion and an increased resistance to stretch in the absence of EMG activity. ${ }^{8}$ In the latter case, the authors were uncertain whether to attribute these changes to the elastic structures or the contractile apparatus. In this study, we did not record EMG activity and therefore cannot exclude a neural contribution to the increased stiffness observed. Even so, our experiments did not produce any evidence for associated changes of active contraction kinetics and would therefore indirectly support the first alternative. This increase in passive elastic stiffness may be a consequence of a failure to use the whole range of joint excursions during daily life of Parkinsonian patients.

This work was supported by the Deutsche Forschungsgemeinschaft (SFB 325). The authors are grateful to Drs G Deuschl, $S$ Fellows and J Noth for reviewing the manuscript.

1 Delwaide PJ, Schwab RS, Young RR. Polysynaptic spina reflexes in Parkinson's disease. Neurol (Minneap) 1974;24:820-7.

2 Delwaide PJ. Are there modifications in spinal cord function of parkinsonian patients? In: Delwaide PJ, Agnoli A, eds. Clinical neurophysiology in Parkinson's disease . contribution to assessment and pathophysiology, vol 2 , Restorative. to assessment and pathophysiology

3 Andrews CJ, Burke D, Lance WJ. The response to muscle stretch and shortening in Parkinsonian rigidity. Brain 1982;95:795-812.

4 Tatton WG, Lee RG. Evidence for abnormal long-loop reflexes in rigid Parkinsonian patients. Brain Res 1975;100:671-6.

5 Mortimer JA, Webster DD. Relationships between quantitative measures of rigidity and tremor and the electromyographic responses to load perturbations in unselected normal subjects and Parkinsonian patients. In: Desmedt JE, ed. Progress in Clinical Neurophysiology, vol 4 Cerebral motor control in man: long-loop mechanisms. Basel: Karger, 1978:342-60.

6 Rothwell JC, Obeso JA, Traub MM, Marsden CD. The behaviour of the long-latency stretch reflex in patients with Parkinson's disease. J Neurol Neurosurg Psychiatry 1983;46:35-44.

7 Dietz V, Quintern J, Berger W. Electrophysiological studies of gait in spasticity and rigidity. Brain 1981;104:431-49.

8 Watts RL, Wiegner AL, Young RR. Elastic properties of muscles measured at the elbow in man: II. Patients with muscles measured at the elbow in man: II. Patients with
Parkinsonian rigidity. $J$ Neurol Neurosurg Psychiatry Parkinsonian rig

9 Hufschmidt A, Mauritz K-H. Chronic transformation of muscle in spasticity: a peripheral contribution to increased muscle in spasticity: a peripheral contribution to increase
tone. J Neurol Neurosurg Psychiatry 1985;48:676-85.

10 Lieber R, Johansson CB, Vahlsing HL, Hargens AR, Feringa E. Long-term effects of spinal cord transsection on fast and slow rat skeletal muscle. Exp Neurol 1986;91:423-34. 
11 Buller AJ, Eccles JC, Eccles RM. Interactions between motoneurones and muscles in respect of the characteristic
speeds of their responses. $J$ Physiol (London) 1960;176:337-54.

12 Close R. Effects of cross-union of motor nerves to fast and slow skeletal muscle. Nature (Lond) 1965;206:831-2.

13 Close R. Dynamic properties of fast and slow skeletal muscles of the rat after nerve cross-union. J Physiol (Lom) 1969;204:331-46.

14 Luff AR. Dynamic properties of fast and slow skeletal muscle in the cat and rat following cross-reinnervation. $J$ Physiol (London) 1975;248:83-96.

15 Lømø T, Westgaard RH. Contractile properties of muscle: control by pattern of muscle activity in the rat. Proc $R$ Soc (London) 1974;187:99-103.

16 Pette D, Smith ME, Staudte HE, Urbova G. Effects of long term electrical stimulation on some contractile and metabolic characteristics of fast rabbit muscles. Pflügers Arch 1973;338:257-72.

17 Pette D, Müller W, Leisner E, Urbova G. Time dependan effects on contractile properties, fibre population, myosin effects on contractile properties, fibre population, myosin mittently and continuously stimulated fast twitch muscles of the rabbit. Pflugers Arch 1976;364:103-12.

18 Hopf HC Herbort RI, Gnass M, Günther H, Lowitzsch K Fast and slow contraction times associated with fast and slow spike conduction of skeletal muscle fibres in normal subjects and spastic hemiparesis. $Z$ Neurol 1974;206: subjects

19 Young JL, Mayer RF. Physiological alterations of motor units in hemiplegia. $J$ Neurol Sci 1982;54:401-12.

20 Visser SL, Oosterhoff E, Hermes HJ, Boon KL, Zilvold G. Single twitch contraction curves in patients with spastic hemiparesis in relation to EMG findings. Electromyogr clin Neurophysiol 1985;25:63-71.

21 Edström L. Selective changes in the size of red and white muscle fibres in upper motor neurone lesions and in Parkinsonism. J Neurol Sci 1968;11:537-50.

22 Ahlqvist G, Landin S, Wroblewski $R$. Ultrastructure of skeletal muscle in patients with Parkinson's disease and upper motor lesions. Lab Invest 1975;32(5):673-9.

23 Berardelli A, Hallett M. Shortening reaction of human tibialis anterior. Neurology (Cleveland) 1984;34:242-6.

tibialis anterior. Neurology (Cleveland) 1984;34:242-6.
24 Buchtal F, Schmalbruch H. Contraction times and fibre types in intact human muscle. Acta Physiol Scand types in intact 